Article

\title{
Impact of Tidal Level Variations on Wave Energy Absorption at Wave Hub
}

\author{
Valeria Castellucci *, Mikael Eriksson and Rafael Waters \\ Swedish Centre for Renewable Electric Energy Conversion, Division of Electricity, Ångström Lab., \\ Lägerhyddsvägen 1, Uppsala University, Uppsala 75121, Sweden; mikael.eriksson@angstrom.uu.se (M.E.); \\ rafael.waters@angstrom.uu.se (R.W.) \\ * Correspondence: valeria.castellucci@angstrom.uu.se; Tel.: +46-18-471-5843; Fax: +46-18-471-5810
}

Academic Editor: Stephen Nash

Received: 1 July 2016; Accepted: 11 October 2016; Published: 19 October 2016

\begin{abstract}
The energy absorption of the wave energy converters (WEC) characterized by a limited stroke length - like the point absorbers developed at Uppsala University-depends on the sea level variation at the deployment site. In coastal areas characterized by high tidal ranges, the daily energy production of the generators is not optimal. The study presented in this paper quantifies the effects of the changing sea level at the Wave Hub test site, located at the south-west coast of England. This area is strongly affected by tides: the tidal height calculated as the difference between the Mean High Water Spring and the Mean Low Water Spring in 2014 was about $6.6 \mathrm{~m}$. The results are obtained from a hydro-mechanic model that analyzes the behaviour of the point absorber at the Wave Hub, taking into account the sea state occurrence scatter diagram and the tidal time series at the site. It turns out that the impact of the tide decreases the energy absorption by $53 \%$. For this reason, the need for a tidal compensation system to be included in the design of the WEC becomes compelling. The economic advantages are evaluated for different scenarios: the economic analysis proposed within the paper allows an educated guess to be made on the profits. The alternative of extending the stroke length of the WEC is investigated, and the gain in energy absorption is estimated.
\end{abstract}

Keywords: wave energy converter (WEC); tides; Wave Hub; energy absorption; economic analysis

\section{Introduction}

The linear generators developed by Uppsala University since 2002 (when the Lysekil research project started) aim to convert the kinematic and potential energy of ocean waves into electricity [1]. In particular, the wave energy converter (WEC) consists of a buoy floating on the water surface and vertically driving the linear generator at the sea floor (see illustration in Figure 1).

Sea water level variations due to tides, changes in barometric pressure, storms, etc. affect the tension in the connection line and the distance between the buoy and the sea floor. For example, during a significant low tide, the connection line is slack and the translator rests on the bottom of the generator; while during a significant high tide, the translator continuously hits the upper end-stop, which results in additional stresses on the hull of the generator and in a reduced stroke of the translator itself. In both cases, the energy absorption decreases drastically, together with the lifetime and survivability of the WEC. The solution to this issue for the Uppsala WEC has been investigated [2]. However, the same problem is also experienced by other wave energy technologies, such as oscillating water columns as described in [3,4], and in more general terms by WECs which have a part that is fixed in position relative to the seabed and a part that moves with the waves. Well-known point absorbers, such as Carnergie CETO [5], Ocean Power Technologies (OPT) Powerbuoy [6], and Archimedes Wave Swing [7] are challenged by the presence of tides, either because of a limited stroke length or because of the exponential decrease in available energy with depth. For this reason, the dependency of the 
energy absorption on the sea level variation is a matter of interest not only for the point absorbers built by Uppsala University, but also for other WEC technologies.

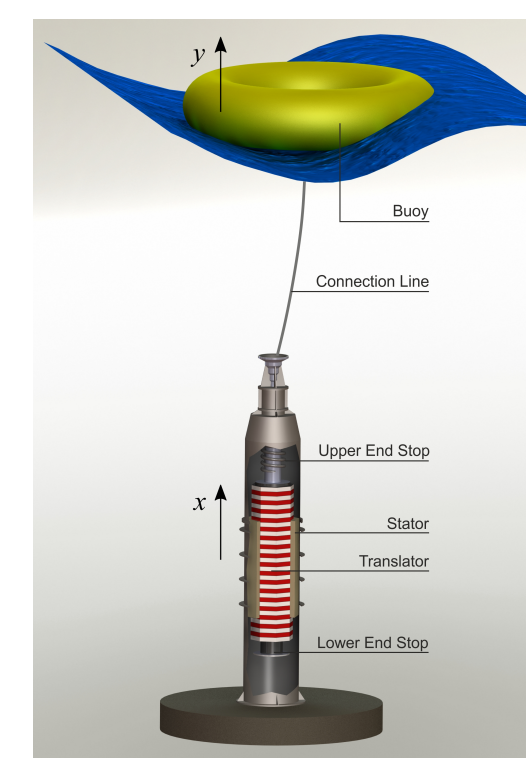

Figure 1. Illustration of the Uppsala wave energy converter (WEC). The linear generator at the seabed is connected via a steel wire to a so-called donut shaped buoy. Note that the buoy used for the analysis conducted in this study is cylindrical.

One of the most interesting locations we could choose to carry out this study is definitely the Wave Hub research site: it is considered the largest grid-connected offshore site in the world available for the development and test of renewable energy technologies [8]. The west coast of the UK is characterized by tides having high range; hence, the area is suitable for many marine current technologies, but could discourage wave energy technologies.

The goal of this study is to quantify the negative effect of the tide at the Wave Hub site for point absorbers with limited stroke length, like the Uppsala wave energy converter.

\section{Method}

This chapter will present the wave climate and tides at the Wave Hub site, describe the hydro-mechanic and economic models developed to estimate the energy absorption and the economic profits, and illustrate the main features of the simulated point absorber.

\subsection{Sea Level Variation at the Wave Hub}

The Wave Hub, located off the coast of Cornwall and characterized by a water depth of $50 \mathrm{~m}$, is the largest and most technically advanced site in the world for offshore renewable energy development: it offers companies and institutions engaged with clean energy projects the opportunity to deploy and to plug their prototypes in to the grid. Consequently, the Wave Hub is a site of interest for many offshore technology developers, including Uppsala University.

The characteristic wave climate of the south-west coast of England is thoroughly described in [9], which presents the wave resource assessment for the Wave Hub based on a 23-year period dataset, obtained by using a high-resolution regional Simulating WAves Nearshore (SWAN) model fed with reanalysis wave and wind data from larger ocean models. The wave climate scatter plot, which shows the occurrence of different combinations of significant wave height, $H_{s}$, and energy periods, $T_{e}$, is presented in Figure 11 of [9]. A condensed diagram is extracted and shown here in Table 1. The diagram is obtained by aggregating the occurrences plotted in the original figure around the nodes 
of a condensed matrix $\left(H_{s}, T_{e}\right)$. Then, the combinations $\left(H_{s}, T_{e}\right)$ with an occurrence greater than $3 \%$ are selected, and the new matrix is normalized in order to get a cumulated occurrence of $100 \%$. The average significant wave height and the energy period, calculated from the spectral moments $m_{0}$ and $m_{-1}$, over 23 years of data was found to be $2 \mathrm{~m}$ and $7 \mathrm{~s}$, respectively [9].

Table 1. Condensed wave climate scatter diagram at the Wave Hub site.

\begin{tabular}{cccccc}
\hline \multirow{2}{*}{$\boldsymbol{H}_{\boldsymbol{s}}(\mathbf{m})$} & \multicolumn{5}{c}{$\boldsymbol{T}_{\boldsymbol{e}}(\mathbf{s})$} \\
\cline { 2 - 6 } & $\mathbf{4}$ & $\mathbf{5}$ & $\mathbf{6}$ & $\mathbf{7}$ & $\mathbf{8}$ \\
\hline $\mathbf{3}$ & - & - & - & $6.0 \%$ & $7.4 \%$ \\
$\mathbf{2}$ & - & - & $14.0 \%$ & $14.6 \%$ & $9.7 \%$ \\
$\mathbf{1}$ & $7.4 \%$ & $15.7 \%$ & $15.5 \%$ & $9.7 \%$ & - \\
\hline
\end{tabular}

The water level variations due to tides on the west coast of Great Britain are among the highest in the world. Figure 2 shows the tidal levels during the first five days of 2014 with a temporal resolution of $1 \mathrm{~h}$ at Newlyn Tidal Observatory, about $22 \mathrm{~km}$ south of the Wave Hub. The maximum yearly variation was registered to be $6.6 \mathrm{~m}$, and the tidal cycle followed a semidiurnal trend, meaning that two tidal cycles occur per day.

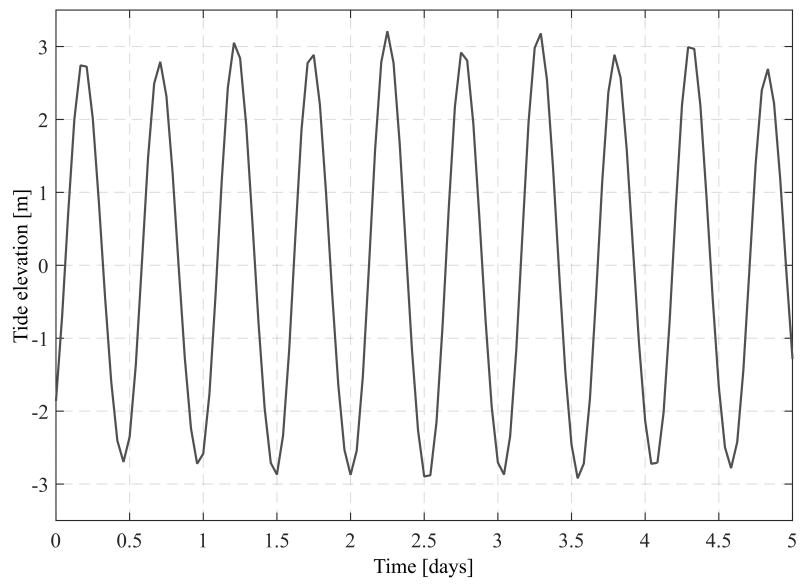

Figure 2. Sea level variation at Newlyn from 1 to 5 January 2014. Credits go to the Sea Level Data Portal hosted by the British Oceanographic Data Centre [10].

\subsection{Hydro-Mechanic Model}

The hydro-mechanic model used to describe the behavior of the WEC couples the buoy hydrodynamic equation of motion with the generator electro-mechanical equation, expressed by Equations (1) and (2), respectively. The buoy is assumed to move in heave only.

$$
\begin{gathered}
m_{b} \ddot{y}=F_{e}-F_{r}+F_{h}-F_{g b}+F_{b}-F_{w} \\
m_{t} \ddot{x}=F_{w}-F_{d}-F_{g t}+F_{e s}
\end{gathered}
$$

where $m_{b}$ and $m_{t}$ are the buoy and the translator masses, $\ddot{y}$ and $\ddot{x}$ are the buoy and translator accelerations, $F_{e}$ and $F_{r}$ are the excitation and radiation forces, $F_{h}$ is the restoring force, $F_{g b}$ and $F_{g t}$ are the gravity forces due to the buoy and translator masses, $F_{b}$ is the buoyancy force, $F_{w}$ is the connection line force between the buoy and the translator, $F_{d}$ is the damping force, and $F_{e S}$ is the end-stop force. These equations are thoroughly explained among others in [11,12]. The description of $F_{w}, F_{e s}$, and $F_{d}$ is given below.

The connection line is modeled as a damped single harmonic oscillator: 


$$
F_{w}= \begin{cases}k_{w}(y-x)+d_{w}(\dot{y}-\dot{x}), & \text { if } y>x \\ 0, & \text { otherwise }\end{cases}
$$

where $k_{w}$ is the spring constant and $d_{w}$ is the damping coefficient of the wire.

The end-stop force is the sum of the contributions of the upper end-stop, the lower end-stop (both modeled as springs), and the upper wall of the WEC capsule. The force exerted by the hull of the WEC is modeled as a stiff damped single harmonic oscillator, which the translator hits when the deformations on the upper end-stop spring become irreversible.

The damping of the generator is defined as:

$$
F_{d}=\gamma \dot{x}
$$

where the damping factor $\gamma$ will be considered constant in the study discussed within this paper.

The Bretschneider spectrum is chosen to generate a time series of polychromatic waves [11]. The parameters used to generate these series are the significant wave height and the energy period:

$$
S(\omega)=\frac{5 \omega_{m}^{4}}{16 \omega^{5}} H_{s}^{2} e^{-5 \omega_{m}^{4} / 4 \omega^{4}}
$$

where $\omega$ is the frequency in radians per second, and $\omega_{m}$ is the modal frequency, a function of $T_{e}$.

The output of the model is illustrated in Figure 3, which shows the displacement of the buoy and the translator, driven by the waves.

When the sea level increases, the motion of the translator is limited by the upper end-stop (Figure 3b); hence, less power will be absorbed by the WEC. When the tide is low enough, the translator rests completely on the lower end-stop.
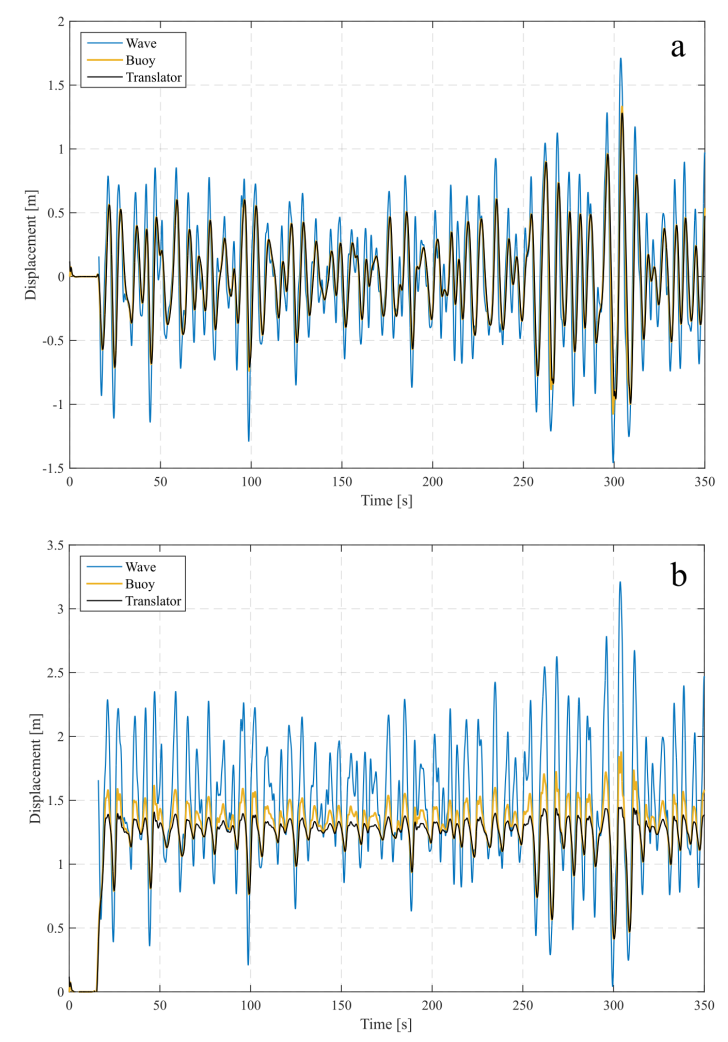

Figure 3. Simulated behavior of the buoy and translator positions in semi-random waves. The tidal level is equal to (a) $0 \mathrm{~m}$; and (b) $+1.5 \mathrm{~m}$. 


\subsection{Wave Energy Converter Design}

The wave energy converters of latest generation use toroidal floaters, but if a compensation system such as the one suggested in [13] is to be included in the future design of WECs, the buoy will most likely be cylindrical in order to facilitate the installation of the system. For this reason, the simulations are carried out using the hydrodynamic parameters calculated by the software WAMIT (WAMIT Inc., Chestnut Hill, MA, USA) for a cylindrical buoy. This buoy is characterized by a radius of $3 \mathrm{~m}$ and a draft of $0.6 \mathrm{~m}$. The generator is placed at $50 \mathrm{~m}$ depth, and it is characterized by a stroke length of the translator equal to $2.46 \mathrm{~m}$. The weight of all the moving parts —excluding the buoy-accounts for 10 tonnes.

Note that the compensation system investigated in [13] consists of a winch that adjusts the length of the connection line via a chain moving on a pocket wheel; however, other mechanical solutions could be adopted.

The energy absorption of the WEC depends on the damping factor, $\gamma$ : given the speed of the translator $\dot{x}$, the power absorption is $P=\gamma \dot{x}^{2}$. The speed $\dot{x}$ is continuously changing during the operation of the WEC, and a real-time control of the damping factor should be considered, as recommended in [14]. To date, a power electronic system that achieves this control has yet to be implemented in the Uppsala wave energy converters. In order to speed up the simulations, $\gamma$ is kept constant during the duration of the simulation, as in Figure 3. Even though the value of the damping coefficient is not optimized here for each wave, a partial optimization has been done for each combination of significant wave height and energy period, as the scatter diagram of Figure 4 shows. In order to calculate the optimum damping factor, $\gamma^{*}$, the integration of $P(\gamma)$ over a year is performed for different values of $\gamma$, and the value $\gamma^{*}$ that gives the best energy absorption for a certain wave climate is plotted in the scatter diagram of Figure 4. Similar calculations have been performed in [15]. The dots marked on the scatter diagram correspond to the most interesting combinations of $H_{s}$ and $T_{e}$ for the Wave Hub site in terms of wave climate occurrence: $73 \%$ of the occurrences fall within the black polygon. The results presented in Section 3 will be based on these specific combinations.

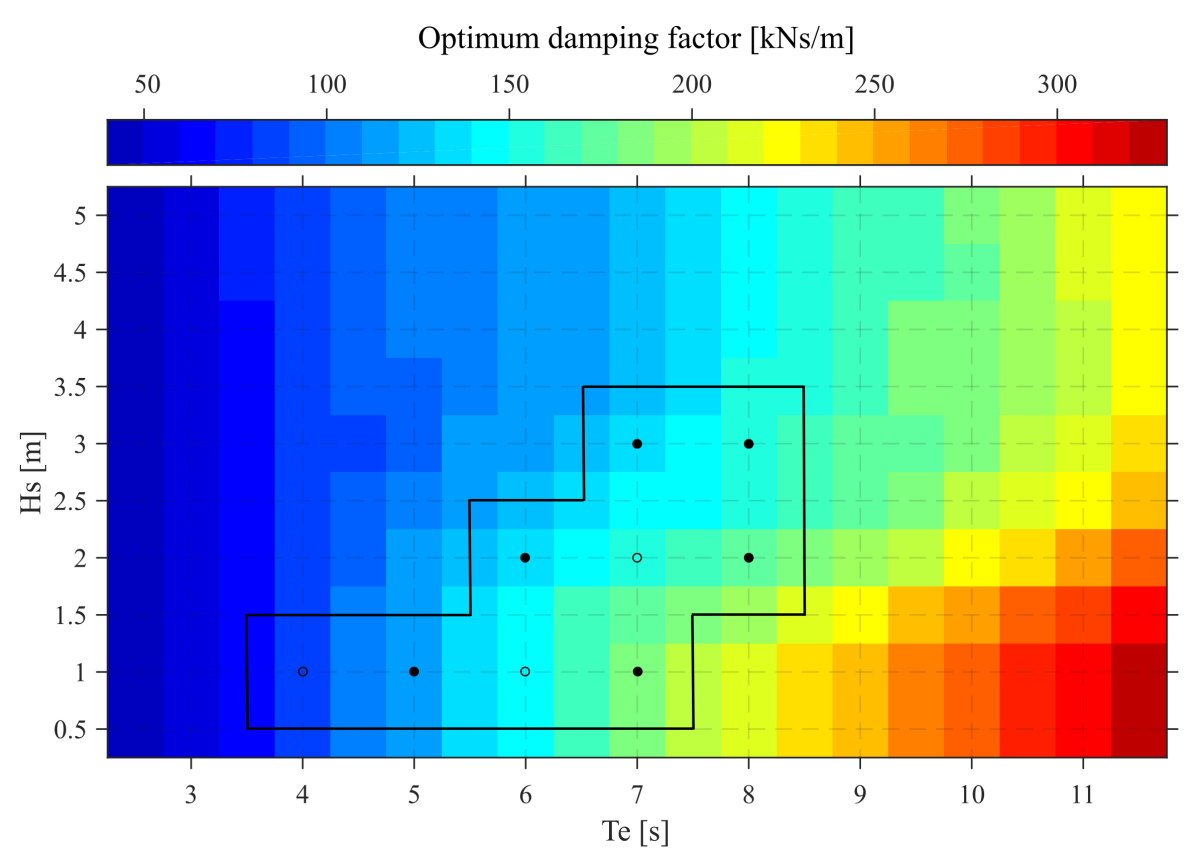

Figure 4. Each combination of $H_{s}$ and $T_{e}$ is characterized by an optimum damping factor that maximizes the WEC energy absorption. The area enclosed in the black polygon corresponds to the area of the wave climate scatter plot containing the most recurrent combinations. 


\subsection{Economic Analysis}

A way of increasing the survivability and energy absorption of the WEC is to include in its design a compensation system for sea level variation. This system reduces the extreme forces on the generator and optimizes the stroke of the translator. However, the system involves a cost due to investment and maintenance that the economic analysis aims to evaluate.

In order for the compensation system to be profitable, the net present value (NPV) defined by Equation (6) has to be positive or at least equal to zero.

$$
N P V=\sum_{i=0}^{N} \frac{C_{i}}{\left(1+r_{d}\right)^{i}}
$$

where $C_{i}$ is the cash flow at year $i$ and $r_{d}$ is the discount rate. This financial indicator helps to calculate the profit of implementing the compensation system in the WEC design, based on the surplus of energy produced and sold to the grid during the 20 year lifetime of the point absorber. The result depends on the surplus of MWh/y produced, but also on the cost of electricity and the discount rate selected, so different scenarios are presented. In particular, the annual energy is set in the range from 0 to $60 \mathrm{MWh}$; the wholesale energy cost with and without feed-in tariffs are assumed to be 0.25 and $0.05 € / \mathrm{kWh}$, respectively [16]; the discount rate for marine energy projects is presumed to range from $8 \%$ to $15 \%$ [17].

\section{Results}

\subsection{Energy Absorption Losses}

The hydro-mechanic model presented in Section 2.2 is used to calculate annual energy absorption of the WEC at the Wave Hub. In order to do this, intermediate steps are taken.

First, the behavior of the WEC is simulated for each wave climate combination presented in Table 1. The input damping coefficient for each $\left(H_{s}, T_{e}\right)$ is chosen from Figure 4 , where the selected combinations are marked with a circle within the black polygon.

Second, the annual energy absorption is calculated as a function of different sea levels, and the bell-shaped curves in Figure 5 are obtained. The same results (in percentage units) are presented in Figure 6 . The wave climate combinations chosen for this figure are the ones marked with a filled circle in Figure 4.

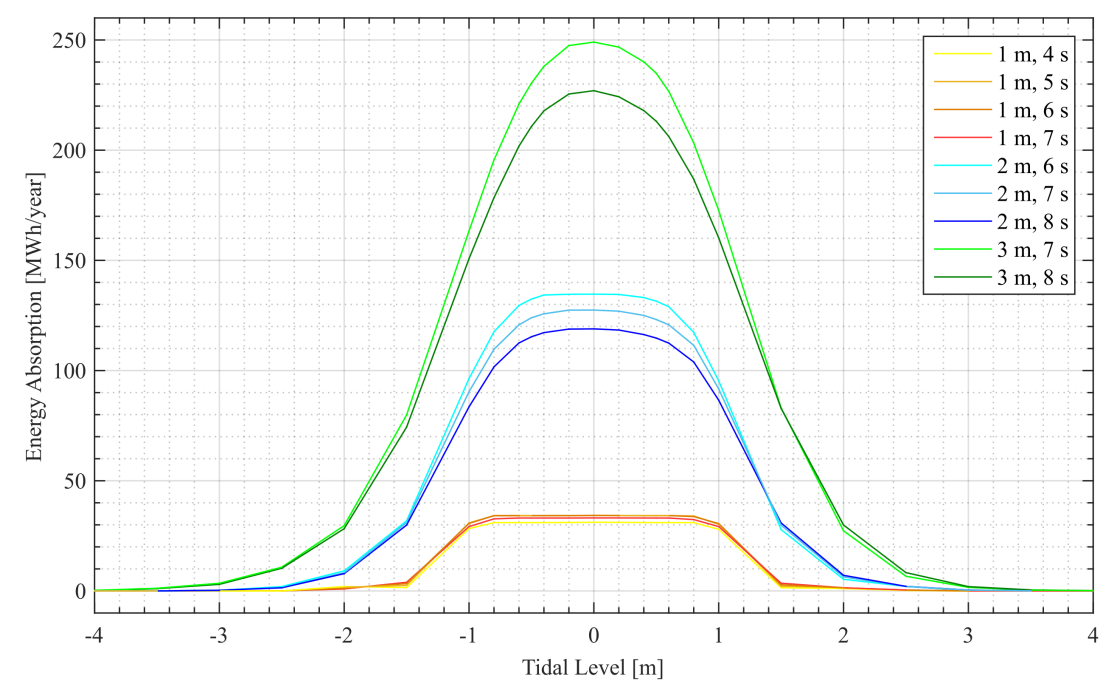

Figure 5. Annual energy absorption of the WEC at different tidal levels and for different combinations of $H_{s}$ and $T_{e}$. 


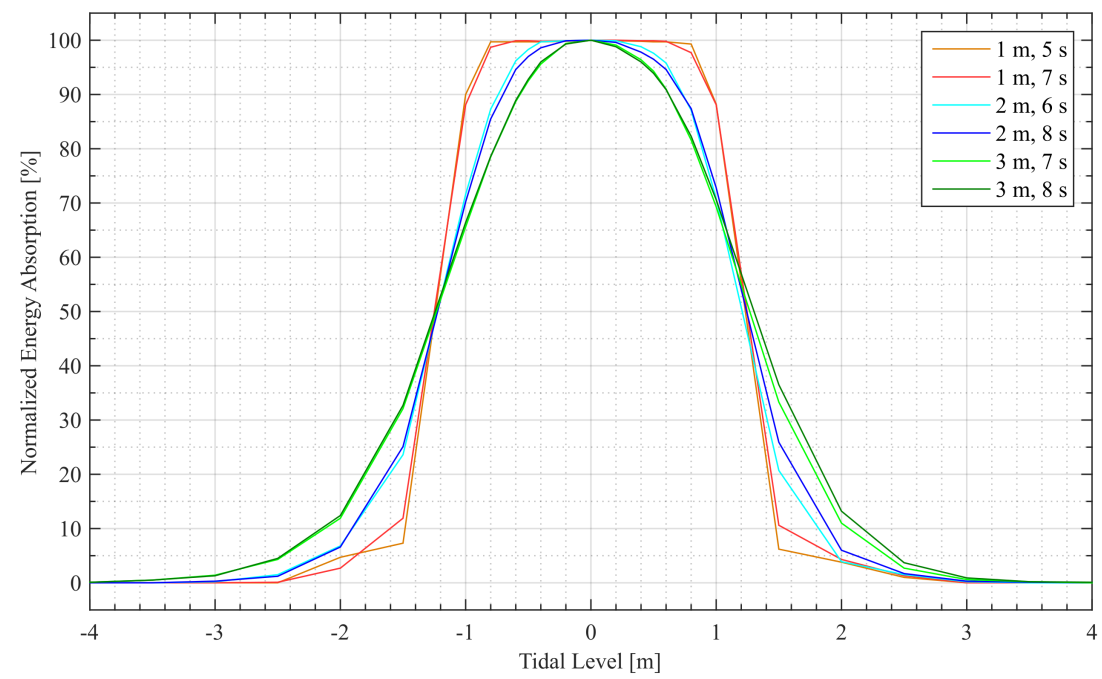

Figure 6. Energy absorption of the WEC in percentage for different tidal levels and different combinations of $H_{s}$ and $T_{e}$. The normalization is carried out for each sea state with respect to the energy absorption at zero tidal level.

Third, the information contained in Table 1 and Figure 5 are combined with the tidal time series shown in Figure 2. The result is the annual energy absorption of the WEC, a function of the different wave climate occurrences and effective sea level variations during the year 2014.

The energy absorption is calculated to be $46 \mathrm{MWh} / \mathrm{y}$ without a compensation system included in the WEC design, and $97 \mathrm{MWh} / \mathrm{y}$ in the case where the sea level variations would be compensated for. This means that the WEC would produce 53\% more energy if equipped with a compensation system.

A sensitivity analysis has been carried out to evaluate how the energy loss varies if the scatter diagram in Table 1 is used, or if just the average significant wave climate calculated over 23 years is considered; i.e., if just one combination of $H_{s}$ and $T_{e}$ is chosen for the year 2014. The difference in energy loss is about $0.5 \%$ : using the significant wave climate instead of the condensed scatter diagram overestimates the energy absorption by approximately $1 \mathrm{MWh} / \mathrm{y}$.

\subsection{Varying the Stroke Length}

As mentioned in Section 2.3, the stroke length of the present generation WEC is about $2.46 \mathrm{~m}$. A way to increase the energy absorption by mitigating the tidal effect is to increase the size of the generator. Figure 7 shows how the energy absorption changes if the stroke length of the translator is increased from 2.5 to $4 \mathrm{~m}$. The simulations are referred to the average significant wave climate ( $2 \mathrm{~m}, 7 \mathrm{~s}$ ). For stroke lengths of $2.5 \mathrm{~m}, 2.7 \mathrm{~m}, 3 \mathrm{~m}, 3.4 \mathrm{~m}$, and $4 \mathrm{~m}$, the energy loss at the Wave Hub would be $53.1 \%, 48.4 \%, 42.6 \%, 35.1 \%$, and $24.5 \%$, respectively, suggesting a linear dependence of the energy absorption on increasing stroke lengths. The linear relation between the energy loss, $E_{\text {loss }}(\%)$, and the stroke length, $l_{s}(\mathrm{~m})$, is calculated to be

$$
E_{\text {loss }}=-18.6 l_{s}+98.5
$$




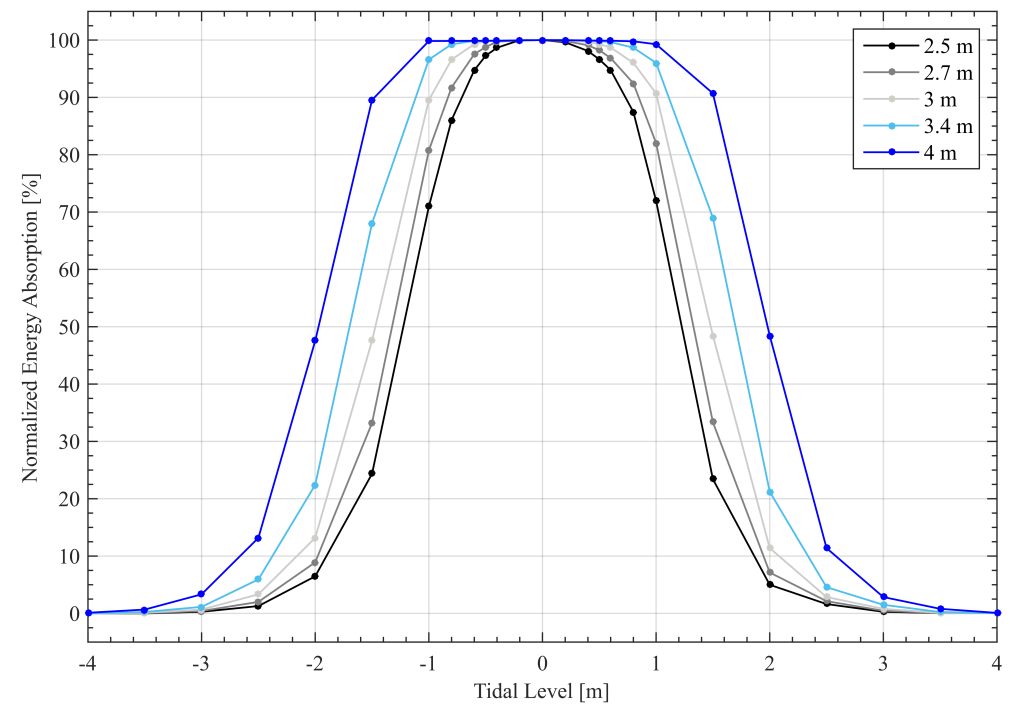

Figure 7. Energy absorption of the WEC in percentage for changing stroke lengths.

\subsection{Economic Profit}

The case study presented here shows that the energy that would have been produced at the Wave Hub with a compensation system during 2014 is about $97 \mathrm{MWh}$, instead of the $46 \mathrm{MWh}$ that the WEC would have produced without it. The resulting $51 \mathrm{MWh}$ difference is used as the input of the analysis to calculate what the corresponding profit would have been. As mentioned in Section 2.4, the profit depends on the discount rate and cost of electricity chosen, and some scenarios are considered and plotted in Figure 8. The graph presents the profit as a function of different surplus of energy absorbed by the WEC thanks to the compensation system. The economic benefit of the system increases if a feed-in tariff is added to the wholesale cost of electricity, and for decreasing discount rates.

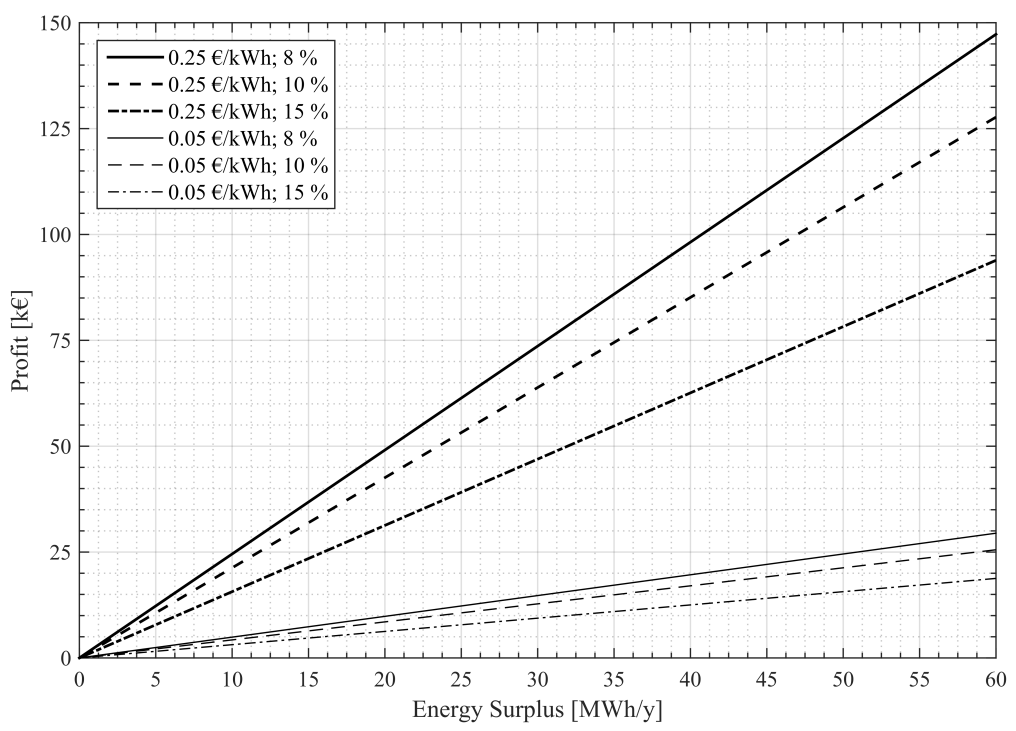

Figure 8. Budget for a compensation sytem as function of the energy surplus, the cost of electricity and the discount rate.

Let us assume that the efficiency of the WEC is $80 \%$, i.e., the energy that could be sold to the grid is about $40.8 \mathrm{MWh} / \mathrm{y}$, that a feed-in tariff of $0.2 € / \mathrm{kWh}$ is added to the electricity price, 
and that the discount rate is $10 \%$. The benefit over 20 years would be $85,000 €$. If the investment (including manufacturing, operation, and maintenance costs) is assumed to be about $12,000 €$, then the pay-back time would be 3 years, and the total profit $73,000 €$. This is just an example of how the graph in Figure 8 should be used, and it helps to make an educated guess of the profit.

\section{Discussion}

The energy absorption of the wave energy converters developed at Uppsala University, as well as of other WEC technologies, depends on the sea level variation at the deployment site. With reference to the present generation WECs designed by the researchers at Uppsala, estimations of energy absorption and losses due to the tidal effect are made in Section 3 and commented on here.

Figure 5 shows how much the tidal level influences the annual energy absorption of the point absorber for different wave climates. The combinations of $H_{s}$ and $T_{e}$ chosen to carry out the estimation are the most recurrent at the Wave Hub site, and the annual energy spans from $30 \mathrm{MWh} / \mathrm{y}$ for low energy waves to $250 \mathrm{MWh} / \mathrm{y}$ for the most powerful sea states. As the significant wave height increases, the energy available at sea (and hence, the energy absorbed by the WEC) increases. Moreover, for the combinations $\left(H_{s}, T_{e}\right)$ considered in Figure 5 , the energy absorption decreases for increasing $T_{e}$, due to the steepness of the waves: the higher $T_{e}$, the lower the wave steepness, and the slower the translator. Furthermore, given the symmetry of the end-stops and the fact that the connection line is never slack thanks to the high weight of the translator, a symmetry in the energy absorption with respect to high and low tides is obtained.

Figure 6 presents the same results of Figure 5 but in units of percentage, and for a selection of $H_{s}$ and $T_{e}$ combinations for ease of graphical representation. The energy absorption for low significant wave heights presents a plateau at low tidal levels; e.g., for $H_{s}=1 \mathrm{~m}$, the energy is constant along the first $\pm 1 \mathrm{~m}$ of tide, and then rapidly drops to almost zero. For increasing $H_{s}$, the plateau becomes less and less evident, and the steepness of the bell-shaped curves decreases, suggesting a lower sensibility of the energy absorption with tidal level variation.

The sea level time series at Newlyn (a station close to the Wave Hub) during 2014 was registered to range from +3.4 to $-3.2 \mathrm{~m}$. Using the hourly time series (Figure 2), the energy absorption curves (Figure 5), and the wave climate scatter diagram (Table 1), the energy absorption of the WEC is calculated. During 2014, the energy that would have been produced is just $46 \mathrm{MWh}$. Including a compensation system in the WEC design would have increased the production to $97 \mathrm{MWh}$. This means that the energy loss accounts for approximately 53\% during 2014, and a similar result is expected for the previous and following years, given the regular pattern of the tides on an annual time scale. Moreover, the same energy loss value is obtained when considering just the combination $H_{s}=2 \mathrm{~m}$ and $T_{e}=7 \mathrm{~m}$ for the whole year and the condensed scatter diagram. Probably, the use of a more detailed scatter diagram for the simulations would not have changed this result significantly either.

In order to mitigate the negative effect of sea level variations on the energy absorption of the WEC, the first intuitive solution would be to increase the stroke length, $l_{s}$, of the translator. Figure 7 shows that extending $l_{s}$ from 2.5 to $4 \mathrm{~m}$ would increase the energy absorption up to $67 \%$ if the tide were in the range $\pm 1.5 \mathrm{~m}$. If $l_{s}$ were increased just from 2.5 to $3.4 \mathrm{~m}$, and a tide of amplitude $1 \mathrm{~m}$ ware considered, then the energy absorption would increase by $46 \%$. This means that for relatively small tides, designing a generator with a longer stroke length could be considered as a solution. For higher sea level variations, like those at the Wave Hub, extending the $l_{s}$ would result in a linearly increasing energy absorption, but also in having the buoy submerged or freely floating for several hours every day. In other words, the energy absorption would not be optimized, and the translator would be hitting the upper end-stop anyway, causing high stresses on the hull of the generator. A different solution should be adopted for the Wave Hub site: the connection line should be adjusted during the tidal cycle to keep the translator moving with the waves.

In order to obtain the results presented in this paper, some simplifications were made and are here discussed. First, the hydrodynamic model is based on the linear wave theory, which loses its validity 
in the case of wave run-up and for breaking waves. In order to take these aspects into consideration, a different and less computationally-expensive model should be used. This would also allow the simulation of a varying damping factor in Equation (4) to better reflect reality. Second, the wave climate at the site was reduced to a condensed scatter diagram, which may introduce an error due to the fact that the generator performs rather well for the most common wave climates or vice versa. The decision to use a condensed scatter diagram comes from the necessity of speeding up the simulations. Third, the economic analysis is useful to make an estimation of the budget that a potential wave energy developer can count on. Of course, a more accurate estimation of the net profit of installing a compensation system can be obtained once more information about manufacturing, operational, and maintenance costs is available.

\section{Conclusions}

The study presented in this paper aimed to quantify the effect of sea level variations on the energy absorption of one WEC; in particular, the point absorber developed at Uppsala University. A hydro-mechanic model was used to simulate the average power absorbed by the WEC for different wave climates, after optimizing the damping factor for each of them. The tides and the wave climate at the Wave Hub test site were selected as input parameters to the simulations. This case study was chosen because it is an interesting location for many wave power developers, and it is significantly affected by the tides.

The results show that the energy loss at the site would have been 53\% in 2014. Most likely, a very similar result would be obtained for previous and future years. The absolute values of energy absorption are presented, but they depend on the features of the WEC that have been simulated. The design of the WEC could change and improve in the near future; hence, the focus should shift to values expressed in percentage.

A feature that could be modified is the stroke length of the translator. For this reason, the positive effect of longer strokes is calculated. Even though the tidal effect can be highly mitigated, the costs, the manufacturing challenges, and the limited benefit could discourage the consideration of this strategy as the only solution.

The economic analysis shows that the investment cost of a tidal compensation system for the Wave Hub site could be very interesting to consider. However, more specific information on discount rate, operation and maintenance costs, and feed-in tariffs should be given to obtain a quantitative result on the net profits.

In order for the technology developed by Uppsala University to be utilized in critical areas such as like the Wave Hub site, a solution to maximize the energy absorption and to minimize the mechanical stresses on the generators should be investigated. Once the solution is found, the point absorbers will be ready to be deployed at any coastal site.

Acknowledgments: The authors would like to thank the Swedish Energy Agency, the ÅForsk Foundation and the Carl Tryggers Foundation for their financial support.

Author Contributions: Valeria Castellucci contributed by collecting the data, developing the hydro-mechanic and economic models, analyzing the results and writing the article. Mikael Eriksson helped by developing the hydro-mechanic model and supervising the work. Rafael Waters provided financial support.

Conflicts of Interest: The authors declare no conflict of interest.

\section{References}

1. Leijon, M.; Boström, C.; Danielsson, O.; Gustafsson, S.; Haikonen, K.; Langhamer, O.; Strömsted, E.; Stålberg, M.; Sundberg, J.; Svensson, O.; et al. Wave energy from the North Sea: Experiences from the Lysekil research site. Surv. Geophys. 2008, 29, 221-240.

2. Castellucci, V.; Abrahamsson, J.; Kamf, T.; Waters, R. Nearshore tests of the tidal compensation system for point-absorbing wave energy converters. Energies 2015, 8, 3272-3291. 
3. López, I.; Pereiras, B.; Castro, F.; Iglesias, G. Performance of OWC wave energy converters: Influence of turbine damping and tidal variability. Int. J. Energy Res. 2015, 39, 472-483.

4. Muetze, A.; Vining, J.G. Ocean wave energy conversion-A survey. In Proceedings of the IEEE Industry Applications Conference, Tampa, FL, USA, 8-12 October 2006.

5. Kenny, S. Carnegie Wave Energy; Internship Report; Murdoch University: Perth, Australia, 2014.

6. Ocean Power Technologies (OPT). Available online: http://www.oceanpowertechnologies.com (accessed on 5 February 2016).

7. Beirdol, P.; Valério, D.; Costa, J.S.D. Linear model identification of the Archimedes Wave Swing. In Proceedings of the International Conference on Power Engineering, Energy and Electrical Drives, Setubal, Portugal, 12-14 April 2007.

8. Wave Hub Limited. Available online: http://www.wavehub.co.uk (accessed on 5 February 2016).

9. Van Nieuwkoop, J.C.C.; Smith H.C.M.; Smith G.H.; Johanning, L. Wave resource assessment along the Cornish coast (UK) from a 23-year hindcast dataset validated against buoy measurements. Renew. Energy 2013, 58, 1-14.

10. British Oceanographic Data Centre. Available online: http://www.bodc.ac.uk (accessed on 2 February 2016).

11. Castellucci, V.; García-Terán, J.; Eriksson, M.; Padman, L.; Waters, R. Influence of sea state and tidal height on wave power absorption. IEEE J. Ocean. Eng. 2016, doi:10.1109/JOE.2016.2598480.

12. Eriksson, M.; Waters, R.; Svensson, O.; Isberg, J.; Leijon, M. Wave power absorption: Experiments in open sea and simulation. J. Appl. Phys. 2007, 102, doi:10.1063/1.2801002.

13. Ayob, M.N.; Castellucci, V.; Terzi, M.; Waters, R. Tidal effect compensation system design for high range sea level variations. In Proceedings of the 11th European Wave and Tidal Energy Conference, Nantes, France, 6-11 September 2015.

14. Ekström, R.; Ekergård, B.; Leijon, M. Electrical damping of linear generators for wave energy converters: A review. Renew. Sustain. Energy Rev. 2015, 42, 116-128.

15. Li, W.; Isberg, J.; Engström, J.; Waters, R.; Leijon M. Parametric study of the power absorption for a linear generator wave energy converter. J. Ocean Wind Energy 2015, 2, 248-252.

16. Paillard, M.; Lacroix, D. Marine Renewable Energies: Prospective Foresight Study for 2030; Editions Quae: Montpellier, France, 2009.

17. Carbon Trust. Future Marine Energy. Results of the Marine Energy Challenge: Cost Competitiveness and Growth of Wave and Tidal Stream Energy; Carbon Trust: London, UK, 2006.

(C) 2016 by the authors; licensee MDPI, Basel, Switzerland. This article is an open access article distributed under the terms and conditions of the Creative Commons Attribution (CC-BY) license (http:/ / creativecommons.org/licenses/by/4.0/). 